\title{
Pengaruh Kualitas Pelayanan dan Fasilitas Lahan Parkir terhadap Kepuasan Civitas Kampus
}

\section{The Impact of Service Quality and Parking Area Facilities on Campus Community Satisfaction}

\author{
Asep Erik Nugraha ${ }^{*}$, Kusnadi ${ }^{1}$, Sarah Dampang ${ }^{2}$ \\ ${ }^{1}$ Program Studi Teknik Industri, Universitas Singaperbangsa Karawang, Jl. H. S. Ronggowaluyo, Telukjambe \\ Timur, Karawang 41361, Indonesia \\ ${ }^{2}$ Program Studi Teknik Kimia, Universitas Singaperbangsa Karawang, Jl. H. S. Ronggowaluyo, Telukjambe \\ Timur, Karawang 41361, Indonesia
}

Diterima: 15 Februari, 2019 / Disetujui: 27 Februari, 2019

\begin{abstract}
The demand for accessible parking services and facilities are growing in the University of Singaperbangsa Karawang (Unsika). This occurred due to the increasing number of vehicles need parking spaces. Some problems can happen because of scrambling over the space, the improper of parking lot building, the ineffective actions in allocating and checking the traffic signs, and the unavailability of traffic signs. The focus of this research was the campus community who use the parking lot. They became the object of the research. The data analysis was used to determine the level of the satisfaction of the campus community towards the service quality and parking facilities in Unsika using the Wilcoxon Signed Rank Test method with Statistical Product and Service Solutions (SPSS) application. The results showed that the campus community was complaining about the quality of service and parking facilities. The perceptions were given in the form of negative perceptions because it was not in line with expectations. The respondents were hoping that the university would pay attention to the quality of services and facilities.
\end{abstract}

Keywords: Campus community, Services, Parking lots, Wilcoxon Test Signed Rank

\begin{abstract}
ABSTRAK
Kebutuhan akan pelayanan dan fasilitas parkir bagi kendaraan akan terus meningkat, dengan meningkatnya jumlah kesadaraan yang ada di lingkungan Universitas Singaperbangsa Karawang (Unsika). Beberapa hal yang perlu diperhatikan dari masalah fasilitas parkir, seperti halnya berebut tempat parkir, ketidaklayakan lahan parkir, tidak efektif dalam penataan dan pengecekan tanda parkir, serta kurangnya rambu-rambu. Penelitian ini berfokus pada civitas kampus sebagai pengguna kendaraan yang dijadikan sebagai objek penelitian. Analisis data ini digunakan untuk mengetahui tingkat kepuasan civitas kampus terhadap kualitas pelayanan dan fasilitas lahan parkir di Unsika dengan metode Uji Wilcoxon Signed Rank menggunakan aplikasi Statistical Product and Service Solutions (SPSS). Hasil penelitian menunjukan bahwa keluhan pengendara atas kualitas pelayanan dan fasilitas lahan parkir denganp persepsi yang diberikan berupa persepsi negative karena tidak sesuai dengan harapan. Responden sangat mengharapkan agar pihak perguruan tinggi memperhatikan atribut kualitas jasa tersebut.
\end{abstract}

Kata Kunci: Civitas kampus, Pelayanan, Lahan parkir, Uji Wilcoxon Signed Rank

\section{PENDAHULUAN}

Pertumbuhan dan perkembangan jumlah kendaraan bermotor sangat pesat saat ini namun tidak diimbangi dengan perkembangan dan perbaikan terhadap infrastruktur baik sarana maupun prasarana, sehingga terjadi ketidakseimbangan dan tanpa disadari hal ini menjadi salah satu indikator penyebab terjadinya berbagai macam masalah yang ditimbulkan salah satunya adalah masalah fasilitas parkir (Parasuraman, Zeithaml dan Berry, 1988). Kebutuhan akan fasilitas parkir

*email: nugraha_ae@yahoo.co.id 
bagi kendaraan akan terus meningkat sejalan dengan meningkatnya jumlah keadaraan yang ada di lingkungan Universitas Singaperbangsa Karawang.

Lahan parkir di lingkungan Universitas Singaperbangsa Karawang merupakan salah satu prioritas yang sangat penting, dengan mengingat banyaknya jumlah mahasiswa yang menggunakan kendaraan meningkat dari tahun ke tahun. Ada hal yang menarik mengenai masalah fasilitas parkir ini, yaitu (Bell et al., 1997):

1. Lahan parkir yang cukup luas belum bisa menyelesaikan masalah penataan parkir di setiap tempat parkir.

2. Para pengendara diharuskan mencari dan berebut tempat parkir sehingga kemungkinan terjadinya tabrakan akan semakin besar.

3. Kondisi lahan parkir yang berlubang mengakibatkan terjadinya ketidaknyamanan saat terjadi hujan yakni banjir.

4. Pengelolaan lahan parkir masih bersifat manual sehingga sering terjadi kesalahan dalam pengelolaannya.

5. Kurang tertibnya dalam proses pecatatan dan pengecekan slip bukti parkir, maka akan memakan waktu sehingga tidak efisien, keenam; rambu lalu lintas dan marka jalan yang tersedia di sekitar kampus tersedia hanya sedikit.

Dengan fakta di lapangan, hal ini dapat dilihat di lingkungan Universitas Singaperbangsa Karawang. Maka dari itu, perguruan tinggi dituntut harus mampu memenuhi kebutuhan civitas kampus sehingga perlu meningkatkan kualitas melalui evaluasi di dalam perguruan tinggi tersebut (Musanto, 2004). Evaluasi merupakan upaya memperbaiki kualitas perguruan tinggi di Indonesia lebih khususnya di Universitas Singaperbangsa Karawang. Perbaikan ini dilakukan menyeluruh terhadap unsur-unsur yang terkait di dalamnya. Kepuasan civitas kampus harus menjadi dasar dari keputusan, sehingga perguruan tinggi harus menjadikan peningkatan kepuasan civitas kampus sebagai sasaran yang mendasar. Oleh karena itu, hasil penelitian yang dilakukan ini nantinya akan dianalisis menggunakan metode Uji Wilcoxon Signed Rank dalam bahasan NonParametrik dan aplikasi Statistical Products and Service Solution (SPSS) (Priyastama, 2005). Pergujian tersebut bertujuan untuk mengetahui kepuasan civitas kampus akan kualitas pelayanan dan fasilitas lahan parkir yang telah diberikan. Persepsi yang nantinya diberikan oleh mahasiswa dapat berupa persepsi positif maupun negatif yang tentunya akan menunjukkan sesuai fakta di lapangan.

\section{METODOLOGI}

Metode pengumpulan data yang digunakan dalam penelitian ini adalah wawancara. Wawancara dilakukan di lingkungan Universitas Singaperbangsa Karawang, untuk melengkapi data yang mendukung penelitian mengenai kualitas pelayanan dan fasilitas lahan parkir terhadap tingkat kepuasan civitas kampus. Observasi, untuk mengumpulkan data penelitian yang dilakukan dengan mengadakan pengamatan secara langsung di lapangan untuk mendapatkan bukti-bukti yang dapat mendukung dan melengkapi hasil penelitian serta pemahaman tentang tingkat kepuasan civitas kampus (tujuan diedarkan kuesioner pada responden adalah untuk memperoleh data mengenai kualitas pelayanan dan fasilitas lahan parkir yang diterapkan oleh Universitas Singaperbangsa Karawang. Penyebaran kuesioner didasarkan pada skala Likert dengan menggunakan 5 opsi jawaban, yaitu: (1) sangat setuju/sangat puas, (2) setuju/puas, (3) Kurang setuju/kurang puas, (4) tidak setuju/tidak puas, dan (5) sangat tidak setuju/sangat tidak puas.

Variabel bebas dalam penelitian ini adalah kualitas pelayanan dan fasilitas lahan parkir dan variabel yang dipengaruhi atau yang menjadi akibat, karena adanya variabel bebas. Sementara itu, variabel terikat adalah kepuasan civitas kampus (Kotler dan Keller, 2016). Populasi pada penelitian ini adalah populasi pengendara yang selama ini menggunakan jasa pelayanan dan fasilitas lahan parkir di Unsika (Sumarni dan Wahyuni, 2006). Pada suatu pengukuran selalu membutuhkan sampel atribut. Sampel atribut merupakan suatu prosedur yang mana hanya mengambil sebagian dari populasi. Untuk menentukan jumlah sampel atribut penelitian, maka digunakan perhitungan Bernoulli ukuran sampel minimum ditampilkan pada persamaan (1) (Walpole et al., 2016).

$$
n \geq \frac{\left(Z^{\propto} / 2\right)^{2} p q}{e^{2}}
$$

Keterangan:

$N$ : Jumlah sampel minimum 
$Z$ : Nilai distribusi normal

$\alpha$ : Tingkat keyakinan

$e \quad$ : Tingkat ketelitian

$p$ : Proporsi jumlah kuesioner yang dianggap benar

$q$ : Proporsi jumlah kuesioner yang dianggap salah

Kuesioner dikatakan valid apabila pertanyaan pada kuesioner dapat mempresentasikan atau mengukur apa yang menunjukkan validitas dari sesuatu yang akan diukur. Tinggi rendahnya validitas pada pertanyaan-pertanyaan menunjukkan sejauh mana mengukur suatu data agar tidak menyimpang dari gambaran variabel yang dimaksudkan agar validitas tercapai. Rumus yang digunakan ditampilkan pada persamaan (2).

$$
r=\frac{N \sum X Y-\left(\sum X \sum Y\right)}{N \sum X^{2} N \sum Y^{2}-\left(\sum Y\right)^{2}}
$$

Keterangan:

$R=$ koefisien korelasi

$X=$ skor butir

$Y=$ skor butir

$N=$ jumlah sampel (responden)

Pada penelitian ini uji reliabilitas dilakukan dengan rumus Cronbach-Alpha seperti ditunjukkan pada persamaan (3). Kriteria reliabilitas yang digunakan adalah apabila nilai hasil hitung uji reliabilitas lebih atau sama dengan 0,6 maka kuesioner dapat dinyatakan reliabel dan dapat digunakan untuk pengambilan data penelitian selanjutnya.

$$
\propto=\frac{(K \times r)}{(1+(K-1) r)}
$$

Keterangan:

$\mathrm{K}$ : Jumlah variabel yang dianalisis

$\mathrm{R}$ : Rata-rata korelasi antara variabel

Analisis data ini digunakan untuk mengetahui tingkat kepuasan civitas kampus terhadap kualitas pelayanan dan fasilitas lahan parkir di Unsika dengan metode Uji Wilcoxon Signed Rank dan menggunakan aplikasi Statistical Product and Service Solutions (SPSS). Analisis data sendiri merupakan suatu usaha untuk menentukan jawaban atas pertanyaan tentang rumusan dan hal-hal yang diperoleh dalam waktu penelitian dan yang sudah masuk dan sudah terkumpul dianalisis untuk menjawab tujuan dari penelitian.

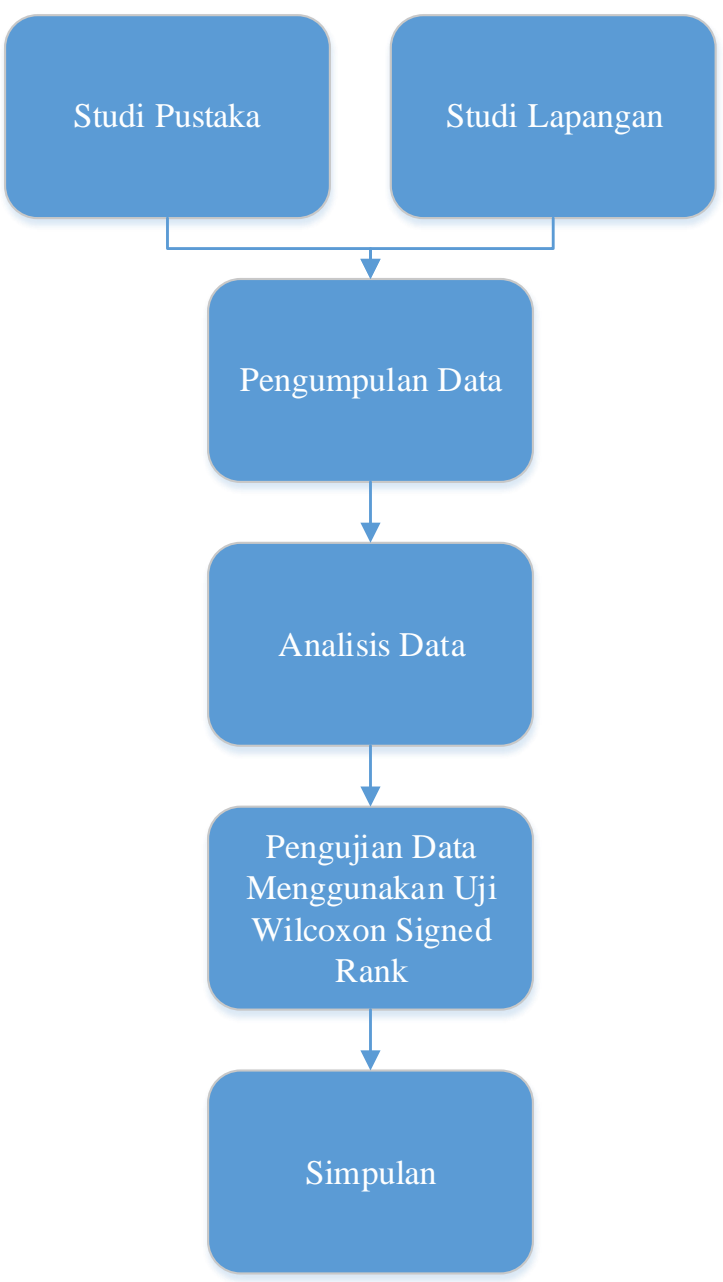

Gambar 1. Flowchart Penelitian

\section{HASIL DAN PEMBAHASAN}

Tahap ini menyajikan hasil pengumpulan data dan analisis data yang telah diperoleh untuk selanjutnya dibahas. Data-data tersebut adalah data kualitatif. Data kualitatif yaitu suatu informasi mengenai pertanyaan-pertanyaan pada tingkat kepuasan civitas kampus terhadap kualitas pelayanan dan fasilitas lahan parkir di Unsika. Data tersebut digunakan dalam pembuatan kuesioner yang berfokuskan terhadap kepuasan civitas kampus, yang selanjutnya dibagikan kepada civitas kampus sebagai pengguna lahan parkir di Universitas Singaperbangsa Karawang. Dari seluruh kuesioner yang dibagikan, responden mengisi kuesioner tersebut dengan baik dan data dapat 
digunakan seluruhnya sesusai dengan yang diharapkan.

Berdasarkan pengamatan yang telah dilakukan mengenai jumlah masuk dan keluarnya kendaraan di lingkungan kampus Universitas Singaperbangsa Karawang. Hal ini dilakukan untuk mengetahui penyebab masalah fasilitas parkir di Unsika, dapat dilihat pada Tabel 1.

Tabel 1 Tabel Data Keluar-masuk Kendaraan

\begin{tabular}{|c|c|c|c|c|c|}
\hline \multirow[b]{2}{*}{ No. } & \multirow{2}{*}{$\begin{array}{c}\text { Jam } \\
\text { Pengama } \\
\text { tan }\end{array}$} & \multicolumn{2}{|c|}{ Mobil } & \multicolumn{2}{|c|}{ Motor } \\
\hline & & $\begin{array}{l}\text { Mas } \\
\text { uk }\end{array}$ & $\begin{array}{l}\text { Kelu } \\
\text { ar }\end{array}$ & $\begin{array}{l}\text { Mas } \\
\text { uk }\end{array}$ & $\begin{array}{l}\text { Kelu } \\
\text { ar }\end{array}$ \\
\hline 1 & $\begin{array}{l}07.00- \\
08.00\end{array}$ & 12 & 3 & 71 & 20 \\
\hline 2 & $\begin{array}{l}08.00- \\
09.00\end{array}$ & 11 & 3 & 164 & 69 \\
\hline 3 & $\begin{array}{l}09.00- \\
10.00\end{array}$ & 25 & 7 & 338 & 141 \\
\hline 4 & $\begin{array}{l}10.00- \\
11.00\end{array}$ & 23 & 13 & 335 & 162 \\
\hline 5 & $\begin{array}{l}11.00- \\
12.00\end{array}$ & 9 & 8 & 267 & 142 \\
\hline 6 & $\begin{array}{l}12.00- \\
13.00\end{array}$ & 8 & 7 & 266 & 188 \\
\hline 7 & $\begin{array}{l}13.00- \\
14.00\end{array}$ & 9 & 7 & 330 & 178 \\
\hline 8 & $\begin{array}{l}14.00- \\
15.00\end{array}$ & 1 & 5 & 320 & 198 \\
\hline 9 & $\begin{array}{l}15.00- \\
16.00\end{array}$ & 2 & 2 & 186 & 159 \\
\hline 10 & $\begin{array}{l}16.00- \\
17.00\end{array}$ & 0 & 2 & 48 & 26 \\
\hline & Total & 100 & 57 & 2325 & 1283 \\
\hline
\end{tabular}

Dapat diketahui dari Tabel 1 bahwa pada jam 09:00-10:00 sampai dengan 10:00-11:00 banyaknya jumlah mobil yang masuk pada jam tersebut. Berbeda halnya pada jam 16:00-17:00 tidak ada mobil masuk, namun ada mobil yang keluar sebanyak 2 mobil. Hal ini dikarenakan pada jam 07:00-08:00 sampai dengan 10:0011:00 merupakan jam kerja, sedangkan pada jam 16:00-17:00 merupakan jam pulang kerja.

\subsection{Uji Kecukupan Data}

Pada tahap pertama dilakukan penyebaran kuesioner awal sebanyak 45 kuesioner. Hal ini dilakukan untuk memastikan bahwa kuesioner tersebut sudah dapat dimengerti dengan baik oleh responden. Dari 45 kuesioner awal yang disebarkan ternyata didapatkan hasil yang tidak kembali sebanyak 2 kuesioner, sehingga yang kembali sebanyak 43 kuesioner dan didapatkan hasil sebagai berikut:

$$
\begin{aligned}
\mathrm{p}= & \frac{\text { (Jumlah sampel yang benar })}{\text { Total jumlah sampel }} \\
& =\frac{43}{45}=0,95 \\
\mathrm{q} & =(1-\mathrm{p})=(1-0,95)=0,05 \\
n & =\left[\frac{1.96}{0.05}\right]^{2} 0.95(1-0.95) \\
= & 72.9904=73 \text { Responden }
\end{aligned}
$$

Dapat diketahui dari hasil perhitungan diatas bahwa jumlah sampel minimum yang harus disebar adalah sebanyak 73 responden, yang dimana penyebaran kuesioner tahap 2 merupakan tahap sampling (Forbes et al., 2011).

\subsection{Uji Validitas}

Dapat diketahui dari setiap variabel yang dihipotesakan akan diukur korelasinya dan dibandingkan dengan angka kritisnya, Dari perhitungan diperoleh $r_{\text {tabel }}$ (product moment) sebesar 0,227. Jika hasil $r_{\text {hitung }}$ lebih besar dari $r_{\text {tabel }}(0,227)$ yang berarti valid (Walpole et al., 2016).

\subsection{Uji Reliabilitas}

Tabel 2 merupakan hasil uji reliabilitas persepsi dan harapan kualitas pelayanan dan fasilitas lahan parkir. Dapat diketahui dari Tabel 4 bahwa nilai $\alpha_{\text {hitung }}$ untuk kuesioner tingkat persepsi dan tingkat harapan diperoleh hasil lebih besar dari pada $\alpha_{\text {tabel }}$ yaitu (0.227) (Walpole, 2011). maka dapat disimpulkan bahwa hasil kuesioner adalah reliabel.

Tabel 2. Reliabilitas Persepsi dan Harapan Kualitas Pelayanan dan Fasilitas Lahan Parkir

\begin{tabular}{lccl}
\hline & $\begin{array}{c}\boldsymbol{\alpha} \\
\text { Hitung }\end{array}$ & $\begin{array}{c}\boldsymbol{\alpha} \\
\text { Tabel }\end{array}$ & Keterangan \\
\hline $\begin{array}{l}\text { Tingkat } \\
\text { Persepsi }\end{array}$ & 0.936 & 0.227 & Reliabel \\
$\begin{array}{l}\text { Tingkat } \\
\text { Harapan }\end{array}$ & 0.953 & 0.227 & Reliabel \\
\hline
\end{tabular}

Dapat diketahui dari semua atribut pada Tabel 3. telah memenuhi syarat perhitungan uji Wilcoxon sehingga didapat $\mathrm{W}_{+}=0$ dan $W_{-}=$ 325. Dikarenakan $W_{+}>W_{-}$, maka diambil $\mathrm{W}_{+}=0$ (nilai terkecil dari nilai absolut hasil penjumlahan merupakan nila thitung yaitu nilai uji statistik) (Montgomery dan Runger, 2018). Kesimpulannya, tolak $H_{0}$, Berdasarkan hasil 
tersebut diperoleh bahwa hasil nilai uji statistik $\leq t_{\text {tabel }}$ yaitu $0 \leq 90$ sehingga disimpulkan bahwa tingkat persepsi mengenai kualitas pelayanan dan fasilitas lahan parkir terhadap kepuasan civitas kampus di Universitas Singaperbangsa Karawang dapat dikatakan tidak sesuai dengan harapan.

Tabel 3. Tabel Peringkat Persepsi dan Terhadap Lahan Parkir

\begin{tabular}{|c|c|c|c|c|c|c|}
\hline \multirow{2}{*}{ Atribut Pelayanan } & \multirow{2}{*}{ Persepsi } & \multirow{2}{*}{ Harapan } & \multirow{2}{*}{$d_{i}$} & \multirow{2}{*}{$\mathrm{I} d_{i} \mathrm{I}$} & \multicolumn{2}{|c|}{ Peringkat } \\
\hline & & & & & $(+)$ & $(-)$ \\
\hline 1 & 3,01 & 4,37 & $-1,36$ & $-1,36$ & & 23 \\
\hline 2 & 3,00 & 4,33 & $-1,33$ & 1,33 & & 22 \\
\hline 3 & 3,14 & 4,19 & $-1,05$ & 1,05 & & 16 \\
\hline 4 & 2,82 & 4,12 & $-1,30$ & 1,30 & & 21 \\
\hline 5 & 3,15 & 4,26 & $-1,11$ & 1,11 & & 17 \\
\hline 6 & 2,99 & 4,23 & $-1,25$ & 1,25 & & 20 \\
\hline 7 & 3,9 & 4,23 & $-0,33$ & 0,33 & & 1 \\
\hline 8 & 2,7 & 4,38 & $-1,68$ & 1,68 & & 25 \\
\hline 9 & 3,84 & 4,45 & $-0,62$ & 0,62 & & 4 \\
\hline 10 & 3,27 & 4,27 & $-1,00$ & 1,00 & & 14 \\
\hline 11 & 3,26 & 4,30 & $-1,04$ & 1,04 & & 15 \\
\hline 12 & 3,45 & 4,32 & $-0,86$ & 0,86 & & 11 \\
\hline 13 & 2,90 & 4,33 & $-1,42$ & 1,42 & & 24 \\
\hline 14 & 3,42 & 4,22 & $-0,79$ & 0,79 & & 7 \\
\hline 15 & 3,52 & 4,44 & $-0,92$ & 0,92 & & 13 \\
\hline 16 & 3,84 & 4,38 & $-0,55$ & 0,55 & & 3 \\
\hline 17 & 3,58 & 4,47 & $-0,89$ & 0,89 & & 12 \\
\hline 18 & 3,41 & 4,23 & $-0,82$ & 0,82 & & 9 \\
\hline 19 & 3,15 & 4,29 & $-1,14$ & 1,14 & & 19 \\
\hline 20 & 3,30 & 4,42 & $-1,12$ & 1,12 & & 18 \\
\hline 21 & 3,52 & 4,37 & $-0,85$ & 0,85 & & 10 \\
\hline 22 & 3,84 & 4,30 & $-0,47$ & 0,47 & & 2 \\
\hline 23 & 3,66 & 4,45 & $-0,79$ & 0,79 & & 7 \\
\hline 24 & 3,71 & 4,52 & $-0,81$ & 0,81 & & 8 \\
\hline 25 & 3,74 & 4,37 & $-0,63$ & 0,63 & & 5 \\
\hline Jumlah & & & & & 0 & 325 \\
\hline
\end{tabular}




\section{NPar Tests}

\section{Wilcoxon Signed Ranks Test}

\begin{tabular}{|c|c|c|c|c|}
\hline \multicolumn{5}{|c|}{ Ranks } \\
\hline & & $N$ & Mean Rank & $\begin{array}{l}\text { Sum of } \\
\text { Ranks }\end{array}$ \\
\hline Harapan - Persepsi & $\begin{array}{l}\text { Negative Ranks } \\
\text { Positive Ranks } \\
\text { Ties } \\
\text { Total }\end{array}$ & $\begin{array}{r}0^{\mathrm{a}} \\
25^{\mathrm{b}} \\
0^{\mathrm{c}} \\
25\end{array}$ & $\begin{array}{r}, 00 \\
13,00\end{array}$ & $\begin{array}{r}, 00 \\
325,00\end{array}$ \\
\hline \multicolumn{5}{|c|}{ a. Harapan < Persepsi } \\
\hline \multicolumn{5}{|c|}{ b. Harapan > Persepsi } \\
\hline \multicolumn{5}{|c|}{ c. Harapan = Persepsi } \\
\hline
\end{tabular}

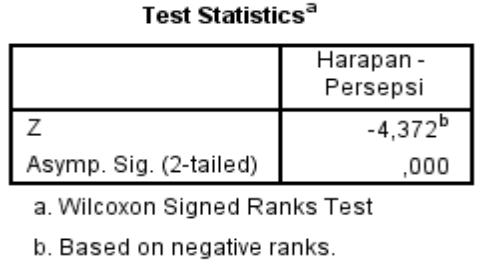

Gambar 2. Pengujian Wilcoxon Signed-Rank

Dapat diketahui dari semua atribut diatas telah memenuhi syarat perhitungan uji Wilcoxon sehingga didapat $\mathrm{W}_{+}=0$ dan $W_{-}=325$. Dikarenakan $\mathrm{W}_{+}>W_{-}$, maka diambil $\mathrm{W}_{+}=0$ (nilai terkecil dari nilai absolut hasil penjumlahan merupakan nila thitung yaitu nilai uji statistik) (Yang, 2014). Kesimpulannya, tolak $H_{0}$, Berdasarkan hasil tersebut diperoleh bahwa hasil nilai uji statistik $\leq t_{\text {tabel }}$ yaitu $0 \leq 90$ sehingga disimpulkan bahwa tingkat persepsi mengenai kualitas pelayanan dan fasilitas lahan parkir terhadap kepuasan civitas kampus dapat dikatakan tidak sesuai dengan harapan.

\section{SIMPULAN}

Penelitian ini menyimpulkan bahwa terdapat pengaruh yang signifikan dari variabel kualitas pelayanan dan fasilitas lahan parkir terhadap kepuasan civitas kampus yakni tingkat persepsi dan harapan pengendara terbesar ada pada dimensi keandalan (reliability) dengan indikator terbesar dibandingkan dengan indikator dari seluruh dimensi kualitas pelayanan yakni memberikan pelayanan yang dilengkapi CCTV pada tempat parkir.

Dalam survei tingkat persepsi dan harapan yang dilakukan kepada 73 pengendara di lingkungan kampus dengan metode Wilcoxon Signed Rank yang telah diuji menggunakan aplikasi SPSS menunjukkan bahwa tingkat persepsi mengenai kualitas pelayanan dan fasilitas lahan parkir terhadap kepuasan civitas kampus dapat dikatakan tidak sesuai dengan harapan. Tanggapan responden sangat mengharapkan agar pihak perguruan tinggi memperhatikan atribut kualitas jasa tersebut.

\section{DAFTAR PUSTAKA}

Bell, M. et al. (1997) Transport Planning and Traffic Engineering. 1 ed. Diedit oleh C. O'Flahety. London: Elsevier Ltd.

Forbes, C. et al. (2011) Statistical Distributions. 4 ed. New Jersey: John Wily and Sons, Inc.

Kotler, P. dan Keller, K. L. (2016) Marketing Management. 15 ed. London: Pearson Education Limited. doi: 10.1080/08911760903022556.

Montgomery, D. C. dan Runger, G. C. (2018) Applied Statistics and Probability for Engineers. 7 ed. New Jersey: John Wily and Sons, Inc.

Musanto, T. (2004) "Faktor-Faktor Kepuasan Pelanggan dan Loyalitas Pelanggan: Studi Kasus pada CV . Sarana Media Advertising Surabaya," Jurnal Manajemen dan Kewirausahaan, 6(2), hal. 123-136.

Parasuraman, A., Zeithaml, V. A. dan Berry, L. L. (1988) "SERVQUAL: A MultipleItem Scale for Measuring Consumer Perceptions of Service Quality," Journal 
of Retailing, 64(1).

Priyastama, R. (2005) Buku Sakti Kuasai SPSS

Pengolahan Data dan Analisis Data. Jakarta: Gramedia Pustaka Utama.

Sumarni, M. dan Wahyuni, S. (2006) Metodologi Penelitian Bisnis. Yogyakarta: Penerbit Andi.
Walpole, R. E. et al. (2016) Probability and Statistics for Engineers and Scientists. 9 ed. London: Pearson Education Limited.

Yang, Z. (2014) A Primer of Probability and Statistics. 3 ed. London: University College London. 